\title{
Chronology of mineralization of the permanent mandibular second molar teeth and forensic age estimation
}

\author{
Pedro Fins $^{1}$ - Maria Lurdes Pereira ${ }^{1,2}$ - Américo Afonso ${ }^{1,3,4}$ - Daniel Pérez-Mongiovi ${ }^{3}$. \\ Inês Morais Caldas ${ }^{1,3,4,5}$ (i)
}

Accepted: 1 May 2017 /Published online: 3 June 2017

(C) Springer Science+Business Media New York 2017

\begin{abstract}
Forensic age estimation frequently relies upon the chronology of mineralization of the third molar teeth. However, even when present, third molar teeth cannot always be used for estimating age in people who are classified as minors. Seconds molars develop earlier and in a more predictable way, and therefore are often more reliable for age estimation in this age group. This study aims to contribute to forensic age estimation using an age threshold of 14-years, studying the stages of development of permanent mandibular second molar teeth mineralization. 367 orthopantograms of a Portuguese population group, aged between 3 and 19 years, were studied. The stages of mineralization of mandibular permanent second molar teeth were studied following the classification stages proposed by Demirjian et al. Stage descriptive analysis was performed, and associations between age and stage were studied. A logistic regression to determine age over 14 years, using maturation stages and sex as a predictive variables, was made. A second sample was used for testing the model. The significance level was set at 5\%. The model
\end{abstract}

Inês Morais Caldas

icaldas@fmd.up.pt

1 Faculdade de Medicina Dentária da Universidade do Porto, Rua Dr. Manuel Pereira da Silva, 4200-393 Porto, Portugal

2 ISPUP - EPIUNit - Instituto de Saúde Pública da Universidade do Porto, 4050-600 Porto, Portugal

3 IINFACTS - Institute of Research and Advanced Training in Health Sciences, Department of Sciences, CESPU, University Institute of Health Sciences (IUCS), Gandra, Portugal

4 CENCIFOR - Centre of Forensic Sciences, University of Coimbra, 3000-213 Coimbra, Portugal

5 CFE - Centre of Functional Ecology, University of Coimbra, 3000-213 Coimbra, Portugal correctly classified $92.0 \%$ of cases overall. The equation was tested in the second sample, and the results showed that there were no statistical significant differences between the binary real age (i.e. age $<14$ and age $\geq 14$ years) and the estimated age $(p=0.109)$. The developed model is useful for age estimation using 14-years as a threshold. However, stage maturation analyses showed that stage F, in males, and stages $\mathrm{G}$ and $\mathrm{H}$, in both sexes, lead to an estimated age with significant statistical differences from chronological age.

Keywords Forensic age estimation · Dental age estimation · Tooth mineralization $\cdot$ Second molar teeth $\cdot$ Demirjian method

\section{Introduction}

Forensic age estimation in the living has become increasingly important. The increasing flux of migrants without valid identification documents [1], fraud in sports [2,3], and crimes involving pediatric pornography [4] are, among others, some of the situations that may require this kind of expertise. Usually, the thresholds involving forensic age estimation are $14,16,18$ or 21 years, depending on each country's laws [5-8].

Forensic age estimation in the living involved in criminal proceedings should follow specific procedures. These guidelines, developed by the Study Group on Forensic Age Diagnostics, [9] concern the following: 1) physical examination, including sexual maturation; conditions that may affect skeletal and/or dental development; 2) skeletal maturation, including an analysis of an x-ray of the left hand; and 3) oral cavity examination, including analyses of dental maturation. If the skeletal development of the hand is complete, an additional radiological examination of the clavicles should be performed. In regards to dental age estimation, the guidelines 
only state that "dental examination with determination of the dental status and X-ray examination of the dentition" should be performed [9], with no reference made to the methodology that should be used. Commonly, teeth mineralization is preferred over dental eruption chronology because the latter is usually less affected by local factors (such as dental cavities, premature deciduous teeth loss or crowding). Additionally, teeth mineralization seems to be less sensitive to environmental hazards and systemic diseases. Of the various known methods, the method described by Demirjian et al. [10] is one of the most used in age estimation of undocumented minors [6, 11-17]. However, it requires the presence of the first seven lower teeth (left or right), and these teeth are not always present. Additionally, this method frequently overestimates age, potentially because of relationships with ethnicity, socioeconomic status and/or secular trends [18]. Therefore, developing alternative methodologies for forensic age estimation could be very useful. For the 14-year-age threshold, permanent mandibular second molar maturation stages can provide important information. In fact, these teeth erupt between 12 and 14 years, and complete root development is achieved at approximately 14-16 years of age. This makes them suitable for age estimation in the 14-16 year age range [19]. In fact, some authors have stated that the stages of maturation of the permanent mandibular second molar can be used as a robust and valid age marker $[11,19,20]$.

With this study, the authors aim to contribute to the process of forensic age estimation using the mineralization stages of the permanent mandibular second molar teeth.

\section{Materials and methods}

We analyzed 367 orthopantograms (OPGs) belonging to individuals (175 males and 192 females) aged between 3 and 19 years (mean age $=11.44$ years; standard deviation [SD] $=4.50$ ) attending the dental clinic of the Faculty of Dental Medicine of the University of Porto, Portugal. OPGs were done for diagnostic purposes only, not specifically for this study. Age distribution according to sex is depicted in Table 1.

A second sample (S2) was used for testing the model. This sample ( $n=773,45.41 \%$ males, $54.59 \%$ females) also relied upon OPGs from patients of the dental clinic of the Faculty of Dental Medicine of the University of Porto, Portugal, which were similarly performed for diagnostic purposes.

Exclusion criteria for both samples were as follows: a) not being Portuguese; b) absence of both permanent mandibular second molars; c) cavities, endodontic treatment or anomalies of both permanent mandibular second molars; d) OPG images of low quality; and e) OPGs with dental anomalies (number or shape).
Table 1 Sample age distribution according sex $(n=236)$

\begin{tabular}{llll}
\hline Age (in years) & \multicolumn{2}{l}{ Sex } & Total (n) \\
\cline { 2 - 4 } & Male & Female & \\
\hline 3 & 4 & 3 & 7 \\
4 & 6 & 4 & 10 \\
5 & 8 & 9 & 17 \\
6 & 10 & 13 & 23 \\
7 & 12 & 17 & 29 \\
8 & 11 & 15 & 26 \\
9 & 14 & 17 & 31 \\
10 & 8 & 13 & 21 \\
11 & 8 & 12 & 20 \\
12 & 7 & 8 & 15 \\
13 & 6 & 4 & 10 \\
14 & 3 & 5 & 8 \\
15 & 5 & 3 & 8 \\
16 & 6 & 5 & 11 \\
Total (n) & 108 & 128 & 236 \\
\hline
\end{tabular}

Left permanent mandibular second molar (37) maturation stages were analyzed using the stages described by Demirjian et al. [10]. Stage 0 was not described by Demirjian et al., but corresponds to the stage "follicle with no calcification" and was also used. When 37 was absent or presented any of the described exclusion criteria, the right permanent mandibular second molar (47) was analyzed instead. Statistical analysis was performed using the Statistical Package for Social Sciences (SPSS), version 21.0. Intra- and inter-observer agreement was evaluated: the first author classified 20 randomly selected OPGs twice within a week interval, and the last author classified 20 OPGs that were previously analyzed by the first author. The results were analyzed using the Wilcoxon signed rank test. Descriptive analysis, including mean age, standard deviation, mean and minimal and maximal age (in years) for permanent mandibular second molars, was performed. To cope with outliers and/or skew, differences between groups of interest were analyzed using nonparametric tests. Correlation between age and stage of mineralization was evaluated using a Spearman rank order correlation (rho). A chi-square test was used to assess the association between age as equal or superior to 14 and mineralization stage. A model using stage $\mathrm{H}$ attainment as the predictive variable and age as the dependent variable was developed. The obtained equation was tested for age estimation of the 14-year-old threshold using a second sample (S2). Differences between ages were assessed using a Wilcoxon signed rank test. The significance level was set at $5 \%$. 


\section{Results}

Repeated scoring of 20 OPGs revealed no significant inter- or intra-observer differences $(p>0.05)$, and agreement occurred in over $95 \%$ of cases.

Table 2 depicts the age sample distribution, divided by sex, in each stage. Only males, aged 3 and 4, depicted stage 0 ( $n=2$, for both age groups). Stage 1 was only found in males, as well, in the 3-year-old age group $(n=1)$. As for stage $\mathrm{H}$ attainment, females in the 11-year-old group were the first to depict this stage $(n=1)$. In males, stage $\mathrm{H}$ attainment was first verified in the 13-year-old age group.

Tables 3 and 4 present the mean age, standard deviation, standard mean error, and minimal and maximal age (in years) for stages 0 and $\mathrm{A}$ to $\mathrm{H}$ for males and females.

Table 2 Frequency of stage distribution in each age group, divided by sex $(\mathrm{M}=$ males; $\mathrm{F}=$ females $)$

\begin{tabular}{|c|c|c|c|c|c|c|c|c|c|c|}
\hline \multirow[t]{2}{*}{ Age, in years } & \multirow[t]{2}{*}{ Sex } & \multicolumn{9}{|c|}{ Stages } \\
\hline & & 0 & A & B & $\mathrm{C}$ & $\mathrm{D}$ & $\mathrm{E}$ & $\mathrm{F}$ & G & $\mathrm{H}$ \\
\hline \multirow[t]{2}{*}{$3-3.9$} & M & 2 & 1 & 1 & 0 & 0 & 0 & 0 & 0 & 0 \\
\hline & $\mathrm{F}$ & 0 & 0 & 3 & 0 & 0 & 0 & 0 & 0 & 0 \\
\hline \multirow[t]{2}{*}{$4-4.9$} & M & 2 & 0 & 3 & 1 & 0 & 0 & 0 & 0 & 0 \\
\hline & $\mathrm{F}$ & 0 & 0 & 1 & 2 & 1 & 0 & 0 & 0 & 0 \\
\hline \multirow[t]{2}{*}{$5-5.9$} & M & 0 & 0 & 1 & 3 & 4 & 0 & 0 & 0 & 0 \\
\hline & $\mathrm{F}$ & 0 & 0 & 1 & 5 & 2 & 0 & 0 & 0 & 0 \\
\hline \multirow[t]{2}{*}{$6-6.9$} & M & 0 & 0 & 0 & 1 & 8 & 1 & 0 & 0 & 0 \\
\hline & $\mathrm{F}$ & 0 & 0 & 0 & 4 & 9 & 0 & 0 & 0 & 0 \\
\hline \multirow[t]{2}{*}{$7-7.9$} & M & 0 & 0 & 0 & 0 & 12 & 0 & 0 & 0 & 0 \\
\hline & $\mathrm{F}$ & 0 & 0 & 0 & 0 & 11 & 6 & 0 & 0 & 0 \\
\hline \multirow[t]{2}{*}{$8-8.9$} & M & 0 & 0 & 0 & 0 & 3 & 7 & 0 & 0 & 0 \\
\hline & $\mathrm{F}$ & 0 & 0 & 0 & 0 & 5 & 10 & 0 & 0 & 0 \\
\hline \multirow[t]{2}{*}{ 9-9.9 } & M & 0 & 0 & 0 & 0 & 1 & 8 & 5 & 0 & 0 \\
\hline & $\mathrm{F}$ & 0 & 0 & 0 & 0 & 1 & 8 & 7 & 1 & 0 \\
\hline \multirow[t]{2}{*}{$10-10.9$} & M & 0 & 0 & 0 & 0 & 0 & 1 & 4 & 3 & 0 \\
\hline & $\mathrm{F}$ & 0 & 0 & 0 & 0 & 0 & 2 & 7 & 4 & 0 \\
\hline \multirow[t]{2}{*}{$11-11.9$} & M & 0 & 0 & 0 & 0 & 0 & 0 & 3 & 5 & 0 \\
\hline & $\mathrm{F}$ & 0 & 0 & 0 & 0 & 0 & 0 & 4 & 7 & 1 \\
\hline \multirow[t]{2}{*}{$12-12.9$} & M & 0 & 0 & 0 & 0 & 0 & 0 & 1 & 6 & 0 \\
\hline & $\mathrm{F}$ & 0 & 0 & 0 & 0 & 0 & 0 & 1 & 7 & 0 \\
\hline \multirow[t]{2}{*}{ 13-13.9 } & M & 0 & 0 & 0 & 0 & 0 & 0 & 0 & 6 & 0 \\
\hline & $\mathrm{F}$ & 0 & 0 & 0 & 0 & 0 & 0 & 0 & 4 & 0 \\
\hline \multirow[t]{2}{*}{$14-14.9$} & M & 0 & 0 & 0 & 0 & 0 & 0 & 0 & 3 & 0 \\
\hline & $\mathrm{F}$ & 0 & 0 & 0 & 0 & 0 & 0 & 0 & 3 & 2 \\
\hline \multirow[t]{2}{*}{$15-15.9$} & M & 0 & 0 & 0 & 0 & 0 & 0 & 0 & 2 & 3 \\
\hline & $\mathrm{F}$ & 0 & 0 & 0 & 0 & 0 & 0 & 0 & 2 & 1 \\
\hline \multirow[t]{2}{*}{$16-16.9$} & M & 0 & 0 & 0 & 0 & 0 & 0 & 0 & 3 & 2 \\
\hline & $\mathrm{F}$ & 0 & 0 & 0 & 0 & 0 & 0 & 0 & 2 & 3 \\
\hline
\end{tabular}

Table 3 Mean age, standard deviation (SD), standard error of the mean (SEM), maximal (Max) and minimal (Min) age, in years, for males, in each stage

\begin{tabular}{lllllll}
\hline Stage & Mean age & SD & SEM & Max & Min & $\mathrm{n}$ \\
\hline 0 & 3.50 & 0.577 & 0.289 & 4 & 3 & 4 \\
A & 3.00 & 0.000 & 0.000 & 3 & 3 & 1 \\
B & 4.00 & 0.707 & 0.316 & 5 & 3 & 5 \\
C & 5.00 & 0.707 & 0.316 & 6 & 4 & 5 \\
D & 6.61 & 0.994 & 0.188 & 9 & 5 & 28 \\
E & 8.47 & 0.874 & 0.212 & 10 & 6 & 17 \\
F & 10.00 & 1.000 & 0.277 & 12 & 9 & 13 \\
G & 12.68 & 1.806 & 0.341 & 16 & 10 & 28 \\
H & 15.40 & 0.548 & 0.245 & 16 & 15 & 5 \\
\hline
\end{tabular}

Females depicted earlier stage attainment for every stage of root mineralization. The minimum age for stage $\mathrm{H}$ attainment was 11 years in females and 15 years in males.

There was a strong, positive correlation between the permanent mandibular second molar stage and chronological age in both sexes (Spearman rho $=0.953, p<0.001$, for males; Spearman rho $=0.933, p<0.001$, for females).

A logistic regression for predicting age over 14 years was performed. Age was converted to a binary variable (0: age $<14$ years, and 1: age $\geq 14$ years old) and used as the dependent variable; the permanent mandibular second molar (PMSM) was converted into numbers $(\mathrm{A}=1, \mathrm{~B}=2, \mathrm{C}=3$, $\mathrm{D}=4, \mathrm{E}=5, \mathrm{~F}=6, \mathrm{G}=7, \mathrm{H}=8$ ); sex (s) and PMSM were used as predictive variables. The Omnibus Test of Model coefficients was highly significant $(p<0.001$; chi-square 305.740 , with 2 degrees of freedom). The predictive variables explained $57.0 \%$ to $78.2 \%$ of the model variability. The model correctly classified $92.0 \%$ of cases overall. The sensitivity of the model (true positives) was $94.69 \%$, whereas the specificity of the model (true negatives) was $90.76 \%$. The permanent mandibular second molar stage of maturation was a significant

Table 4 Mean age, standard deviation (SD), standard error of the mean (SEM), maximal (Max) and minimal (Min) age, in years, for females, in each stage

\begin{tabular}{lllllll}
\hline Stage & Mean age & SD & SEM & Max & Min & $\mathrm{n}$ \\
\hline 0 & - & - & - & - & - & - \\
$\mathrm{A}$ & - & - & - & - & - & - \\
$\mathrm{B}$ & 4.00 & 1.000 & 0.577 & 5 & 3 & 3 \\
$\mathrm{C}$ & 5.18 & 0.751 & 0.226 & 6 & 4 & 11 \\
$\mathrm{D}$ & 6.69 & 1.072 & 0.199 & 9 & 4 & 29 \\
E & 8.23 & 0.908 & 0.178 & 10 & 7 & 26 \\
F & 9.95 & 0.911 & 0.209 & 12 & 9 & 19 \\
G & 12.20 & 1.827 & 0.334 & 16 & 9 & 30 \\
H & 14.75 & 1.813 & 0.685 & 16 & 11 & 7 \\
\hline
\end{tabular}


variable in the equation $(p<0.001)$, whereas sex was not $(p=0.819)$.

The resulting equation for determining age regarding the 14-year-age threshold was age $=-22.374-0.090 \mathrm{~s}+3.120$ PMSM, with s coded as 1 if male and 2 if female.

If the number obtained is $<1$, the estimated age is under 14 years; if the number obtained is $\geq 1$, the estimated age is $\geq 14$ years.

The equation was then tested in the second sample, S2; no statistically significant differences between the binary real age (i.e. age $<14$ and age $\geq 14$ years) and the estimated age $(p=0.109)$ were verified. However, when analyzing the differences between chronological age and estimated age regarding the 14-year-old threshold by maturation stage, statistically significant differences were found in males in stage $\mathrm{F}$ and in both males and females in stages $\mathrm{G}$ and $\mathrm{H}$ (Table 5).

\section{Discussion}

Legal age attainment happens in some countries at 14 years [21-23]. In Portugal, in particular, this age threshold is important in child abuse. Article $172^{\circ}$ of the Portuguese Penal Code determines different sentences if victims are younger or older than 14 years of age.

Until now, most studies regarding age estimation have focused mainly on the thresholds of 16 and 18 years [12, 24-27]; few papers address the age of 14 years [8, 11, 28, 29]. Still, as stated before, this age threshold may be relevant, and the most often used methods require the existence of the

\begin{tabular}{|c|c|c|c|c|}
\hline \multirow{19}{*}{$\begin{array}{l}\text { between chronological } \\
\text { age and estimated age } \\
\text { regarding the 14-year- } \\
\text { old threshold, according } \\
\text { the maturation stage of } \\
\text { the mandibular } \\
\text { permanent second molar } \\
\text { (Wilcoxon Test) }\end{array}$} & Stage & Sex & Z & $\mathrm{p}$ \\
\hline & 0 & M & - & - \\
\hline & & $\mathrm{F}$ & - & - \\
\hline & A & $\mathrm{M}$ & - & - \\
\hline & & $\mathrm{F}$ & - & - \\
\hline & B & $\mathrm{M}$ & 0.000 & 1.000 \\
\hline & & $\mathrm{F}$ & 0.000 & 1.000 \\
\hline & $\mathrm{C}$ & $\mathrm{M}$ & 0.000 & 1.000 \\
\hline & & $\mathrm{F}$ & 0.000 & 1.000 \\
\hline & $\mathrm{D}$ & M & 0.000 & 1.000 \\
\hline & & $\mathrm{F}$ & 0.000 & 1.000 \\
\hline & $\mathrm{E}$ & $\mathrm{M}$ & 0.000 & 1.000 \\
\hline & & $\mathrm{F}$ & 0.000 & 1.000 \\
\hline & $\mathrm{F}$ & $\mathrm{M}$ & -2.449 & 0.014 \\
\hline & & F & -1.732 & 0.083 \\
\hline & G & $\mathrm{M}$ & -3.000 & 0.003 \\
\hline & & $\mathrm{F}$ & -3.000 & 0.003 \\
\hline & $\mathrm{H}$ & $\mathrm{M}$ & -3.317 & $<0.001$ \\
\hline & & F & -2.646 & 0.008 \\
\hline
\end{tabular}

first seven lower permanent teeth [10, 30, 31]. For instance, Pinchi et al. [29] addressed forensic age estimation of the 14year-old threshold and tested several methods relying on dental calcification of the first seven teeth, namely Demirjian, Willems, Cameriere and Haavikko's methodologies. However, it is not expected that the first six teeth will provide information pertinent to the 14-year-old threshold.

Conversely, the mineralization stages of the permanent mandibular second molar teethhave been correlated with age, in particular with the age of 14 years [32].

Our model correctly classified $92.0 \%$ of cases overall, indicating strong model performance. The sensitivity of the model was also high $(94.69 \%)$, indicating a low occurrence of unacceptable ethical errors. The rate of unacceptable technical errors is expected to be low as well because the specificity of the model was $90.76 \%$. Thus, when our model predicts an age $\geq 14$ years, the age prediction is most likely correct, whereas an age prediction $<14$ years has a slightly higher possibility of error associated with it. These results were also confirmed when the resulting equation was applied to a second sample (S2). Garamendi et al. [13] described these errors as unacceptable technical errors because the estimated age is inferior to the real age, leading to the adoption of less severe punitive measures. However, in the context of pedopornography, considering Portuguese law, these errors may be considered as unacceptable ethical errors as well because the punitive measures are more severe when victims are younger than 14 . Thus, the context in which age estimation is performed must be considered when selecting the methodology; although both errors should be avoided, the unacceptable ethical errors should be reduced to a minimum.

Other studies on second molar development and forensic age estimation have mainly provided reference values concerning age and stage of development [32]. Almeida et al. reported that maturation stages of the permanent mandibular second molar were reached by females earlier than in males in stages B to H. However, in our study, this only happened in the stages concerning root development, possibly indicating different environmental factors [33], ethnic differences or both.

Forensic age estimation using the permanent mandibular second molar stages of eruption have also been studied [8, 28, 30]. Marques et al. [28] stated that complete emergence of permanent mandibular second molars can be used as a dental age indicator of age over 14 years, particularly in males. Still, permanent mandibular second molar complete eruption was attained by $14.8 \%$ and $25.6 \%$ of the males and females younger than 14 years, respectively, again raising problems of unacceptable ethical errors. Additionally, many authors [12, 34-36] agree that teeth mineralization should be favored over teeth eruption because it seems to be a more reliable process that is not as affected by local factors, namely, malnutrition, 
premature loss of primary teeth, crowding and dental decay. Additionally, tooth formation is seen as a more robust measure with high heritability, a low coefficient of variation and a resistance to environmental effects [34]. Thus, techniques based on the mineralization process of teeth should, perhaps, be preferred.

\section{Conclusion}

It is clear that there is a relationship between age and mineralization stages of the permanent mandibular second molar. In our study, we developed a model that can be used to predict age for the 14-year old threshold. However, mineralization stages alone, particularly those concerning root development, should be used with caution because differences between the real age and estimated age arose, suggesting the need for additional methods for age estimation for this threshold.

\section{Key points}

1. Age estimation using 14-years as the threshold can be useful.

2. Second molar teeth mineralization stages are valuable in estimating age using the 14-year threshold.

3. A model can be used for age prediction using the 14-yearage threshold.

4. Stage maturation analyses showed that stages concerning root development may lead to differences between estimated and chronological age.

\section{Compliance with ethical standards}

Funding No funding to report.

Conflict of interest All authors declare no conflict of interest.

Ethical approval All procedures performed in studies involving human participants were in accordance with the ethical standards of the institutional and/or national research committee and with the 1964 Helsinki declaration and its later amendments or comparable ethical standards. No informed consent was obtained since this was a retrospective study based on anonymized clinical records.

\section{References}

1. Chariot $\mathrm{P}$, Caussinus H. Age estimation in undocumented migrant adolescents: medical response to judicial authorities. Presse Med. 2015;44(1):99-100.

2. Wittschieber D, Vieth V, Timme M, Dvorak J, Schmeling A. Magnetic resonance imaging of the iliac crest: age estimation in under-20 soccer players. Forensic Sci Med Pathol. 2014;10(2): 198-202.
3. Timme M, Steinacker JM, Schmeling A. Age estimation in competitive sports. Int J Legal Med. 2017;131(1):225-33.

4. Ratnayake M, Obertova Z, Dose M, Gabriel P, Broker HM, Brauckmann M, et al. The juvenile face as a suitable age indicator in child pornography cases: a pilot study on the reliability of automated and visual estimation approaches. Int $\mathrm{J}$ Legal Med. 2014;128(5):803-8

5. Olze A, Bilang D, Schmidt S, Wernecke KD, Geserick G, Schmeling A. Validation of common classification systems for assessing the mineralization of third molars. Int $\mathrm{J}$ Legal Med. 2005;119(1):22-6.

6. Olze A, van Niekerk P, Schmidt S, Wernecke KD, Rosing FW, Geserick G, et al. Studies on the progress of third-molar mineralisation in a black African population. Homo. 2006;57(3): 209-17.

7. Schmeling A, Olze A, Reisinger W, Rosing FW, Geserick G. Forensic age diagnostics of living individuals in criminal proceedings. Homo. 2003;54(2):162-9.

8. Wedl JS, Schoder V, Blake FA, Schmelzle R, Friedrich RE. Eruption times of permanent teeth in teenage boys and girls in Izmir (Turkey). J Clin Forensic Med. 2004;11(6):299-302.

9. Schmeling A, Grundmann C, Fuhrmann A, Kaatsch HJ, Knell B, Ramsthaler $\mathrm{F}$, et al. Criteria for age estimation in living individuals. Int J Legal Med. 2008;122(6):457-60.

10. Demirjian A, Goldstein H, Tanner JM. A new system of dental age assessment. Hum Biol. 1973;45(2):211-27.

11. Almeida MS, Pontual Ados A, Beltrao RT, Beltrao RV, Pontual ML. The chronology of second molar development in Brazilians and its application to forensic age estimation. Imaging Sci Dent. 2013;43(1):1-6.

12. Caldas IM, Julio P, Simoes RJ, Matos E, Afonso A, Magalhaes T. Chronological age estimation based on third molar development in a Portuguese population. Int J Legal Med. 2011;125(2):235-43.

13. Garamendi PM, Landa MI, Ballesteros J, Solano MA. Reliability of the methods applied to assess age minority in living subjects around 18 years old. A survey on a Moroccan origin population. Forensic Sci Int. 2005;154(1):3-12.

14. Nik-Hussein NN, Kee KM, Gan P. Validity of Demirjian and Willems methods for dental age estimation for Malaysian children aged 5-15 years old. Forensic Sci Int. 2011;204(1-3):208 e1-6.

15. Sisman Y, Uysal T, Yagmur F, Ramoglu SI. Third-molar development in relation to chronologic age in Turkish children and young adults. Angle Orthod. 2007;77(6):1040-5.

16. Lewis JM, Senn DR. Dental age estimation utilizing third molar development: a review of principles, methods, and population studies used in the United States. Forensic Sci Int. 2010;201(1-3):79-83.

17. Lopez TT, Arruda CP, Rocha M, Rosin AS, Michel-Crosato E, Biazevic MG. Estimating ages by third molars: stages of development in Brazilian young adults. J Forensic Legal Med. 2013;20(5): 412-8.

18. Rousset MM, Boualam N, Delfosse C, Roberts WE. Emergence of permanent teeth: secular trends and variance in a modern sample. $\mathrm{J}$ Dent Child (Chic). 2003;70(3):208-14.

19. Balaraj BM, Nithin MD. Determination of adolescent ages 14-16 years by radiological study of permanent mandibular second molars. J Forensic Legal Med. 2010;17(6):329-32.

20. Lee SS, Byun YS, Park MJ, Choi JH, Yoon CL, Shin KJ. The chronology of second and third molar development in Koreans and its application to forensic age estimation. Int J Legal Med. 2010;124(6):659-65.

21. Olze A, Reisinger W, Geserick G, Schmeling A. Age estimation of unaccompanied minors. Part II. Dental aspects. Forensic Sci Int. 2006;159(Suppl 1):S65-7. 
22. Schmeling A, Reisinger W, Geserick G, Olze A. Age estimation of unaccompanied minors. Part I. General considerations. Forensic Sci Int. 2006;159(Suppl 1):S61-4.

23. Thevissen PW, Kvaal SI, Willems G. Ethics in age estimation of unaccompanied minors. J Forensic Odontostomatol. 2012;30(Suppl 1):84-102.

24. Duangto P, Iamaroon A, Prasitwattanaseree S, Mahakkanukrauh P, Janhom A. New models for age estimation and assessment of their accuracy using developing mandibular third molar teeth in a Thai population. Int J Legal Med. 2017;131:559-68.

25. Gulsahi A, De Luca S, Cehreli SB, Tirali RE, Cameriere R. Accuracy of the third molar index for assessing the legal majority of 18 years in Turkish population. Forensic Sci Int. 2016;266(584): e1-6.

26. Cavric J, Galic I, Vodanovic M, Brkic H, Gregov J, Viva S, et al. Third molar maturity index (I3M) for assessing age of majority in a black African population in Botswana. Int J Legal Med. 2016;130(4):1109-20.

27. Caldas IM, Carneiro JL, Teixeira A, Matos E, Afonso A, Magalhaes T. Chronological course of third molar eruption in a Portuguese population. Int J Legal Med. 2012;126(1):107-12.

28. Marques MR, Pereira MD, Caldas IM. Forensic age estimation using the eruption of the second permanent mandibular molar: determining age over 14 years-old. Aust J Forensic Sci. 2015;47(3): 306-12.

29. Pinchi V, Norelli GA, Pradella F, Vitale G, Rugo D, Nieri M. Comparison of the applicability of four odontological methods for age estimation of the 14 years legal threshold in a sample of Italian adolescents. J Forensic Odontostomatol. 2012;30(2):17-25.

30. Karadayi B, Afsin H, Ozaslan A, Karadayi S. Development of dental charts according to tooth development and eruption for Turkish children and young adults. Imaging Sci Dent. 2014;44(2): 103-13.

31. Cameriere R, Pacifici A, Pacifici L, Polimeni A, Federici F, Cingolani M, et al. Age estimation in children by measurement of open apices in teeth with Bayesian calibration approach. Forensic Sci Int. 2016;258:50-4

32. Kumar NN, Panchaksharappa MG, Annigeri RG. Digitized morphometric analysis of dental pulp of permanent mandibular second molar for age estimation of Davangere population. J Forensic Legal Med. 2016;39:85-90.

33. Carneiro JL, Caldas IM, Afonso A, Cardoso HF. Examining the socioeconomic effects on third molar maturation in a Portuguese sample of children, adolescents and young adults. Int J Legal Med. 2017;131:235-42.

34. Liversidge HM, Chaillet N, Mornstad H, Nystrom M, Rowlings K, Taylor J, et al. Timing of Demirjian's tooth formation stages. Ann Hum Biol. 2006;33(4):454-70.

35. Frucht S, Schnegelsberg C, Schulte-Monting J, Rose E, Jonas I. Dental age in southwest Germany. A radiographic study. J Orofac Orthop. 2000;61(5):318-29.

36. Prieto JL, Barberia E, Ortega R, Magana C. Evaluation of chronological age based on third molar development in the Spanish population. Int J Legal Med. 2005;119(6):349-54. 